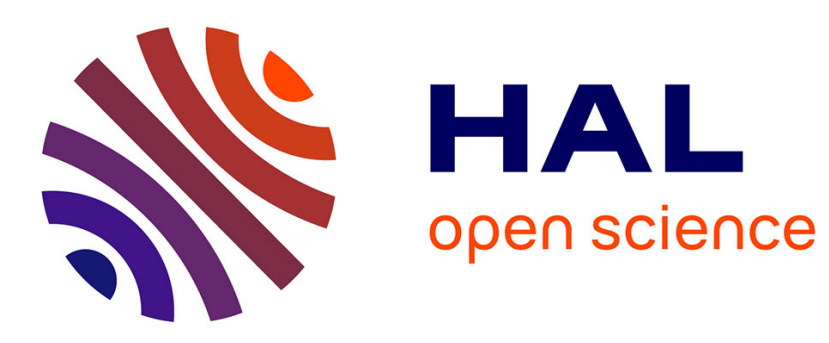

\title{
In Situ Synthesis of Ternary Block Copolymer/Homopolymer Blends for Organic Photovoltaics
}

Fritz Nübling, Dan Yang, Peter Müller-Buschbaum, Martin Brinkmann, Michael Sommer

\section{To cite this version:}

Fritz Nübling, Dan Yang, Peter Müller-Buschbaum, Martin Brinkmann, Michael Sommer. In Situ Synthesis of Ternary Block Copolymer/Homopolymer Blends for Organic Photovoltaics. ACS Applied Materials \& Interfaces, 2018, 10 (21), pp.18149-18160. hal-02045727

\section{HAL Id: hal-02045727 https://hal.science/hal-02045727}

Submitted on 8 Dec 2021

HAL is a multi-disciplinary open access archive for the deposit and dissemination of scientific research documents, whether they are published or not. The documents may come from teaching and research institutions in France or abroad, or from public or private research centers.
L'archive ouverte pluridisciplinaire HAL, est destinée au dépôt et à la diffusion de documents scientifiques de niveau recherche, publiés ou non, émanant des établissements d'enseignement et de recherche français ou étrangers, des laboratoires publics ou privés. 


\section{In-situ synthesis of ternary block copolymer /}

\section{homopolymer blends for organic photovoltaics}

Fritz Nübling $^{\dagger, \dagger}$, Dan Yang ${ }^{\perp}$, Peter Müller-Buschbaum ${ }^{\perp}$, Martin Brinkmann $\|$, Richard Friend ${ }^{ \pm}$, Michael Sommer ${ }^{\dagger, \dagger}, \S^{*}$

$\dagger$ Institut für Makromolekulare Chemie, Albert-Ludwigs-Universität Freiburg, Stefan-MeierStraße 31, 79104 Freiburg, Germany

$\ddagger$ Freiburger Materialforschungszentrum, Albert-Ludwigs-Universität Freiburg, Stefan-MeierStraße 21, 79104 Freiburg, Germany

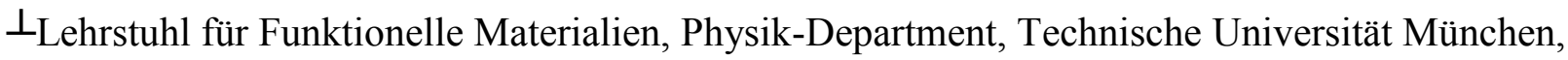
James-Franck-Straße 1, 85748 Garching, Germany

|| Institut Charles Sadron, CNRS-Univeristé de Strasbourg, 23 rue de Loess, 67034 Strasbourg, France

\pm Optoelectronics Group, Cavendish Laboratory, J. J. Thomson Avenue, University of Cambridge, Cambridge, CB3 0HE, United Kingdom

§present address: Technische Universität Chemnitz, Institut für Chemie, Straße der Nationen 62, 09111 Chemnitz, Germany

Email: $\underline{\text { michael.sommer@ chemie.tu-chemnitz.de }}$

KEYWORDS: P3HT, PNDIT2, all-conjugated block copolymer, HRTEM, GIWAXS; GISAXS 


\section{ABSTRACT}

A detailed investigation of in-situ synthesized all-conjugated block copolymer (BCP) compatibilized ternary blends containing poly(3-hexylthiophene) (P3HT) and poly $\{[\mathrm{N}, \mathrm{N}$ '-bis(2octyldodecyl)naphthalene-1,4,5,8-bis(dibcarboximide)-2,6-diyl]-alt-5,5'-(2,2'-bithiophene)\}

(PNDIT2) as donor and acceptor polymers, respectively, is presented. Both polymers are incompatible and show strong segregation in blends, which renders compatibilization with their corresponding $\mathrm{BCPs}$ promising to enable nanometer-phase separated structures suitable for excitonic devices. Here we synthesize a ternary block copolymer / homopolymer blend system and investigate the phase behavior as a function of block copolymer molecular weight and different annealing conditions. Device performance decreases for increasing annealing temperatures. To understand this effect, morphological investigations including atomic force microscopy (AFM), high resolution electron microscopy (HR-TEM) and grazing incidence wideand small-angle x-ray scattering (GIWAXS/GISAXS) are carried out. On comparing domain sizes of pristine and compatibilized blends obtained from GISAXS, a weak compatibilization effect appears to take place for the in-situ synthesized ternary systems. The effect of thermal annealing is much stronger for all systems, which, for the highest annealing temperature above the melting point of PNDIT2 $\left(310{ }^{\circ} \mathrm{C}\right)$, ultimately leads to a change from face-on to edge-on orientation of PNDIT2 as seen in GIWAXS. This effect dominates and decreases all photovoltaic parameters, irrespective of whether a pristine or compatibilized blend is used. 


\section{INTRODUCTION}

Electronic devices made from semiconducting polymers are advantageous in terms of ease of fabrication and low cost production to produce flexible thin film devices. Over the last decades many new polymers have been investigated and intensive research has focused on the development of new donor materials to be combined with small molecules being fullerene or non-fullerene derivatives. ${ }^{1,2}$ Power conversion efficiencies have been improved to above $12 \%$. However, in principle manufacturing the active layer of solar cells with all polymer materials exclusively offers important advantages over the commonly applied polymer-small molecule systems. A possibility for careful tuning complementary light absorption of the donor and acceptor polymers and a more balanced charge carrier mobility of both are fundamental advantages as compared with polymer-small molecule systems. ${ }^{3-5}$ In addition, the mechanical stability has been shown to be superior in case of all polymer systems as compared to polymersmall molecule based films. ${ }^{6}$ In terms of power conversion efficiencies (PCE), high performance all-polymer systems ${ }^{7-10}$ have made significant progress, and have almost matched values for polymer-fullerene $\mathrm{e}^{11,12}$ systems.

Nevertheless, several drawbacks need to be overcome to enable further progress in the field of all polymer solar cells. Most importantly, morphology control is of critical importance. Because of the low permittivity of semiconducting polymers, absorbed photons generate localized and tightly bound excitons with a limited lifetime and thus a short diffusion length of typically less than $15 \mathrm{~nm}$. Within this length scale the donor-acceptor interface must be reached to prevent thermal relaxation to the ground state. ${ }^{13-15}$ In addition to morphological properties, the orientation of the donor and acceptor conjugated polymer chains with respect to each other and to the electrodes, is crucial for e.g. charge injection. Charge transport is usually anisotropic and 
considered to be fast and efficient along the conjugated backbone, slower along the $\pi-\pi$ stacking direction and significantly hindered across the insulating alkyl side chains. ${ }^{16-18}$ As a consequence, edge-on alignment is thought to be favored for horizontal charge transport in thin film transistors, while face-on alignment is beneficial for photovoltaic devices where charge injection into horizontal electrodes is required. ${ }^{19-22}$

The acceptor material (being itself a donor-acceptor copolymer) poly\{[N,N'-bis(2octyldodecyl)naphthalene-1,4,5,8-bis(dibcarboximide)-2,6-diyl]-alt-5,5'-(2,2'-bithiophene)\}

(PNDIT2) shows predominantly face-on orientation in as-cast films ${ }^{21,23,24}$ which turns into edgeon alignment ${ }^{17,25,26}$ after melt-annealing and subsequent cooling. By contrast, poly(3hexylthiophene) (P3HT) favors edge-on ${ }^{27,28}$ orientation after processing from solution leading to orthogonally aligned donor and acceptor phases in melt annealed P3HT/PNDIT2 blend systems. ${ }^{29}$ The relative orientation of polymers can be changed, with several experimental possibilities to tune molecular orientation and phase segregation like thermal annealing ${ }^{30,31}$, additives $^{12}$, choice of solvents ${ }^{29,32}$, blend ratio $^{28,33}$ and others ${ }^{34,35}$ being reported. However, a predetermined control over backbone orientation remains an unsolved challenge that is currently being addressed in the field. ${ }^{34}$

Low efficiency bulk heterojunction devices containing polymers processed from solution form morphologies at the $\mu \mathrm{m}$ length scale and charge traps by inclusions of one phase resulting in incomplete charge extraction and high recombination rates. ${ }^{30,32,36-38}$ In contrast, a bicontinuous network at the nm length scale of phase separated donor and acceptor polymers provides large interfacial area and lower recombination rates for maximized charge separation and extraction. ${ }^{39}$ This is difficult to realize with polymer blend systems because of their low entropy of mixing ${ }^{40}$ which results in strong driving force for phase separation. 
Block copolymers (BCP) form well-defined and thermodynamically stable nanostructures and thus are ideal to achieve the desired morphologies for OPV devices. ${ }^{41-43}$ However, the synthesis of pure, well-defined all-conjugated donor-acceptor BCPs with sufficiently high molar mass and tunable composition remains a challenge. ${ }^{44-47}$ However, experimentally simple phase tuning is possible using compatibilization, which entails the addition of a block copolymer to a blend of the same components. Here, BCPs operate as macromolecular surfactants and tend to locate at the interface to allow smaller domain sizes by reducing interfacial torsion. ${ }^{4-50}$ This approach has been successfully demonstrated for PCDTBT/P3HT ${ }^{35}$ with few percentages of BCP resulting in the compatibilization of the immiscible binary blend systems to yield thermodynamically stable morphologies.

In the present work, the donor/ acceptor system P3HT/ PNDIT2 $29,30,32,36,51-53$ is compatibilized with the corresponding block copolymers P3HT- $b$-PNDIT2. Specifically, the approach employed here relies on the use of in-situ synthesized ternary blends comprising P3HT, PNDIT2 and P3HT- $b$-PNDIT2. These form during the direct arylation polycondensation (DAP) of brominated naphthalene diimide and bithiophene in the presence of end group functionalized P3HT, as reported elsewhere. ${ }^{54}$ The observed optical and thermal properties determined by UV-vis and DSC are beneficial for application in OPV devices. We combine several techniques to probe structure formation of the ternary blends in combination with the investigation of the optoelectronic properties. The central finding of our study is that although a weak compatibilization effect is observed upon BCP addition, the limiting factor is the orientation of the conjugated backbones with respect to the substrate. Melt annealing, which is applied to access stable nanostructures, leads to an edge-on orientation of PNDIT2 which is detrimental to device performance. 


\section{EXPERIMENTAL SECTION}

\section{Materials and Syntheses}

$\mathrm{Pd}_{2} \mathrm{dba}_{3}, \mathrm{Na}_{2} \mathrm{CO}_{3}$ and pivalic acid were purchased from Sigma-Aldrich and used without further purification. Mesitylene was degassed with nitrogen prior to use. Bithiophene was purchased from $\mathrm{ABCR}$ and eluated over $\mathrm{SiO}_{2}$ with iso-hexanes. $\mathrm{NDIBr}_{2}{ }^{55}, \mathrm{H}-\mathrm{P} 3 \mathrm{HT}-\mathrm{Br}^{56}$ and the synthesis of P3HT- $b$-PNDIT2 block copolymers ${ }^{54}$ was carried out according to the literature.

\section{Instruments}

$U V$-vis spectroscopy. UV-vis spectra were recorded at $25^{\circ} \mathrm{C}$ using a Lambda $650 \mathrm{~S}$ spectrometer from Perkin Elmer. Thin films were spin-coated from $12 \mathrm{mg} / \mathrm{ml}$ chlorobenzene solutions onto Spectrosil 2000 quartz glass substrates.

Size exclusion chromatography. SEC measurements of all samples were carried out on four SDV gel $5 \mu \mathrm{m}$ columns with pore sizes ranging from $10^{3}$ to $10^{6} \AA$ (Polymer Standards), connected in series with a Knauer K-2301 RI detector and a G1314-60100 D2 UV detector (Agilent Technologies) calibrated with polystyrene standards. $\mathrm{CHCl}_{3}$ was used as eluent at $22{ }^{\circ} \mathrm{C}$ with a flow rate of $1.0 \mathrm{ml} / \mathrm{min}$. Data analysis was carried out with PSS WinGPC Unichrom version 8. Atomic force microscopy. AFM was carried out on a Vecco Dimension 3100 AFM in tapping mode.

Differential scanning calorimetry. DSC measurements were carried out on a DSC Seiko 6200 (Seiko/Perkin Elmer) under nitrogen atmosphere. Heating and cooling rates were set to $10 \mathrm{~K} / \mathrm{min}$, sample weight was $3-5 \mathrm{mg}$. 
Device fabrication. OPV devices were fabricated to give the following device structure: glass/ITO/PEDOT:PSS/polymer/LiF/Al/glass. ITO covered glass slides were first cleaned with acetone and isopropanol for 10 minutes under ultrasound before treated by oxygen plasma for 20 minutes. PEDOT:PSS was spin-coated to give a $40 \mathrm{~nm}$ layer and annealed at $160{ }^{\circ} \mathrm{C}$ for 20 minutes. The substrates were introduced into a nitrogen-filled glove box. The photoactive polymer layer was spin-coated from $12 \mathrm{mg} / \mathrm{ml}$ chlorobenzene solution to yield $70 \mathrm{~nm}$ thin films, which were subjected to different annealing protocols. Afterwards, hole blocker $\operatorname{LiF}(2.5 \mathrm{~nm})$ has been evaporated on the active layer prior to the aluminum electrode $(\sim 100 \mathrm{~nm})$. Devices have been encapsulated with glass, using epoxy resin.

Device testing. $J-V$ characteristics were measured under AM 1.5 illumination $\left(100 \mathrm{~mW} / \mathrm{cm}^{2}\right)$ using an Abet Technology solar simulator. Currents were recorded using a Keithley 237 source meter. Spectral mismatches of the simulator were calibrated with a silicon reference cell.

Grazing incidence wide-and small-angle X-ray scattering. The grazing incidence wide- and small-angle x-ray scattering (GIWAXS and GISAXS) experiments were performed at beamline P03 of the PETRA III storage ring at DESY, Hamburg, Germany. ${ }^{57}$ The photon energy was 13 $\mathrm{keV}$ corresponding to a wavelength of $0.954 \AA$. The sample-detector distance was $134 \mathrm{~mm}$ in GIWAXS geometry and $3166 \mathrm{~mm}$ in GISAXS geometry. A beam size of $30 \times 26 \mu \mathrm{m}^{2}$ (horizontal×vertical) was selected. A Pilatus 300k area detector was operated at the GIWAXS position and a Pilatus 1M area detector at the GISAXS sample position. Both detectors had a pixel size of $0.172 \mathrm{~mm}$ in horizontal and vertical direction. The incident angle was set to $0.35^{\circ}$ to be well above the critical angles of all involved materials to ensure probing of the full film volume.

High-resolution transmission electron microscopy. HR-TEM was performed in low dose mode 
on a FEI CM12 microscope equipped with a mega view III CCD camera (Soft Imaging System). For sample preparation, the films were first coated with a thin film of amorphous carbon using an Auto 306 Edwards evaporator under high vacuum $\left(10^{-5}-10^{-6} \mathrm{mbar}\right)$. The films were removed from their $\mathrm{Si}(100)$ substrates using polyacrylic acid, floated on distilled water and recovered on TEM copper grids. Thermal treatments of the films on the TEM grids were performed in a linkam LTS420 hot stage $\left(310^{\circ} \mathrm{C}\right.$ for $10 \mathrm{~min}$.) under nitrogen flow. Specific conditions for HRTEM and low dose diffraction are given elsewhere. ${ }^{58}$

\section{RESULTS AND DISCUSSION}

The in-situ synthesis of ternary blends of PNDIT2, P3HT and P3HT- $b$-PNDIT2 is performed using DAP of 2,6-dibromo naphthalene diimide $\left(\mathrm{NDIBr}_{2}\right)$ and bithiophene (T2) in the presence of hydrogen/ mesityl-terminated P3HT (Mes-P3HT-H). The hydrogen-terminated chain end is moderately reactive under the DAP conditions used, and the mesityl end group is unreactive. ${ }^{55}$ This leads to a fraction of Mes-P3HT-H, which terminates PNDIT2 chains leading to block copolymer, with the remaining fraction being P3HT homopolymer. At the same time, incomplete termination of PNDIT2 chains leads to PNDIT2 homopolymer formation also. Using this procedure, a mixture of the homopolymers Mes-P3HT-H and PNDIT2 and the block copolymer Mes-P3HT- $b$-PNDIT2 forms as published recently. ${ }^{54}$ The chemical structures of all compounds are depicted in Figure 1 and the properties of all samples are summarized in Table 1. 


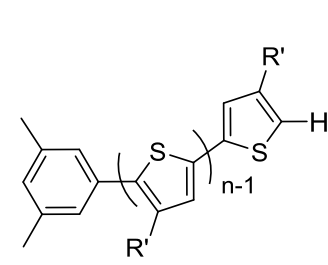

Mes-P3HT-H

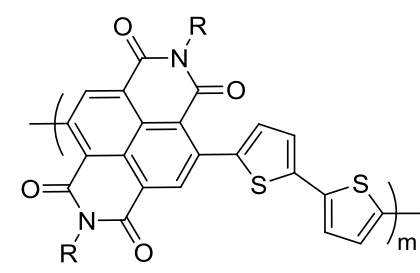

PNDIT2

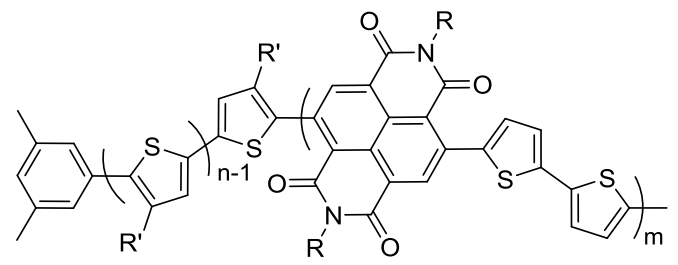

$\begin{array}{ll}\text { Mes-P3HT-PNDIT2 } & \begin{array}{l}R=2-\text { octyldodecyl } \\ R^{\prime}=n \text {-hexyl }\end{array}\end{array}$

Figure 1. Chemical structures of homopolymers Mes-P3HT-H and PNDIT2 and the block copolymer Mes-P3HT-PNDIT2.

Table 1. Molecular weight and composition of ternary samples P1, P2 and P3, and homopolymers Mes-P3HT-H and PNDIT2 used for pristine blends (w:w 1:1).

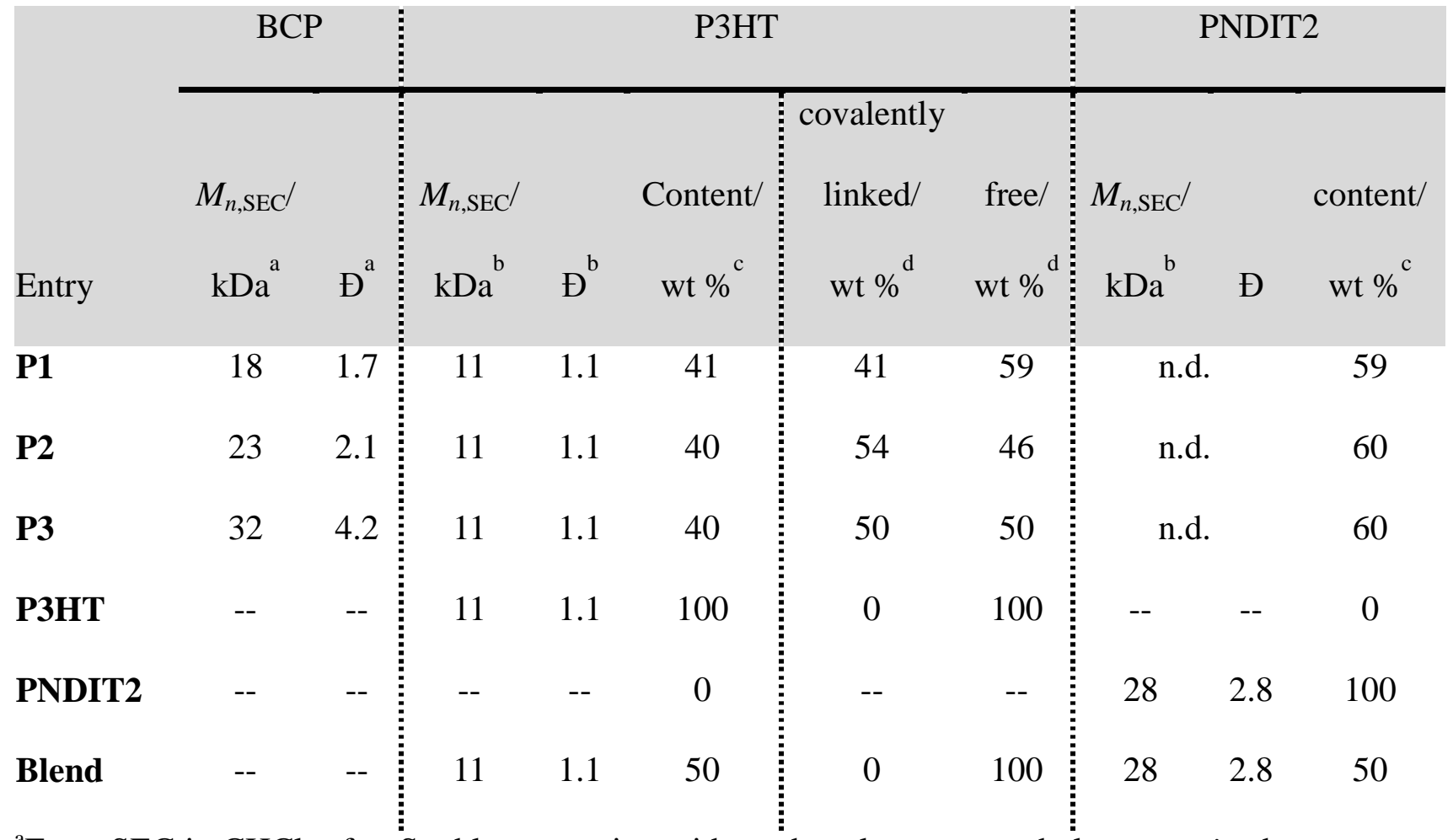

${ }^{a}$ From $\mathrm{SEC}$ in $\mathrm{CHCl}_{3}$ after Soxhlet extraction with methanol, acetone, ethyl acetate, iso-hexanes.

${ }^{\mathrm{b}}$ From SEC in $\mathrm{CHCl}_{3}$ after Soxhlet extraction with methanol, acetone and iso-hexanes. 
${ }^{\mathrm{c}}$ Estimated from ${ }^{1} \mathrm{H}$ NMR integrals of side chain signals at $4.19 \mathrm{ppm}\left(\mathrm{NCH}_{2}\right.$ of NDI) and 2.86 ppm $\left(\alpha-\mathrm{CH}_{2}\right.$ of P3HT). ${ }^{\mathrm{d}}$ Estimated from ${ }^{1} \mathrm{H}$ NMR integrals of linkage signal at $7.18 \mathrm{ppm}$ and P3HT-H end group signal at 6.94 ppm.

All three samples P1, P2 and P3 are synthesized using the same NDIBr2 : T2 : Mes-P3HT-H ratio and therefore exhibit almost the same composition of P3HT and PNDIT2. The samples vary in the number average molecular weight $M_{\mathrm{n}, \mathrm{SEC}}$ from 18 to $32 \mathrm{~kg} / \mathrm{mol}$ (Figure SI-1) and the content of covalently linked P3HT weight ratio, which is between 41 and 54 wt \%. In contrast to $\mathrm{P} 3$, the molecular weights from $\mathrm{P} 1$ and $\mathrm{P} 2$ are smaller than the molecular weight of the homopolymer PNDIT2 used for the pristine blend. The optical properties of the samples in film are investigated by steady-state UV-vis spectroscopy (Figure 2). All films feature the expected superposition of the homopolymers with ideal complementary absorption to cover the entire visible spectrum.

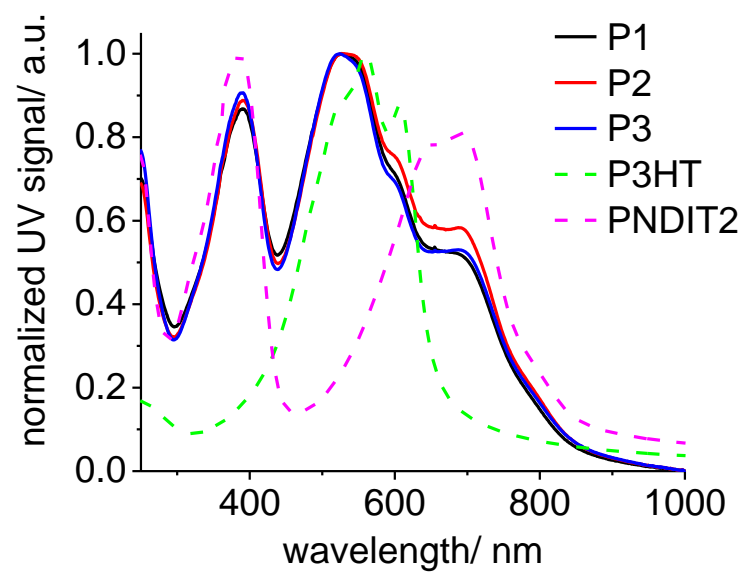

Figure 2. UV-vis spectra of (as spun) films of P1, P2 and P3 and the homopolymers Mes-P3HT$\mathrm{H}$ and PNDIT2 as indicated. 


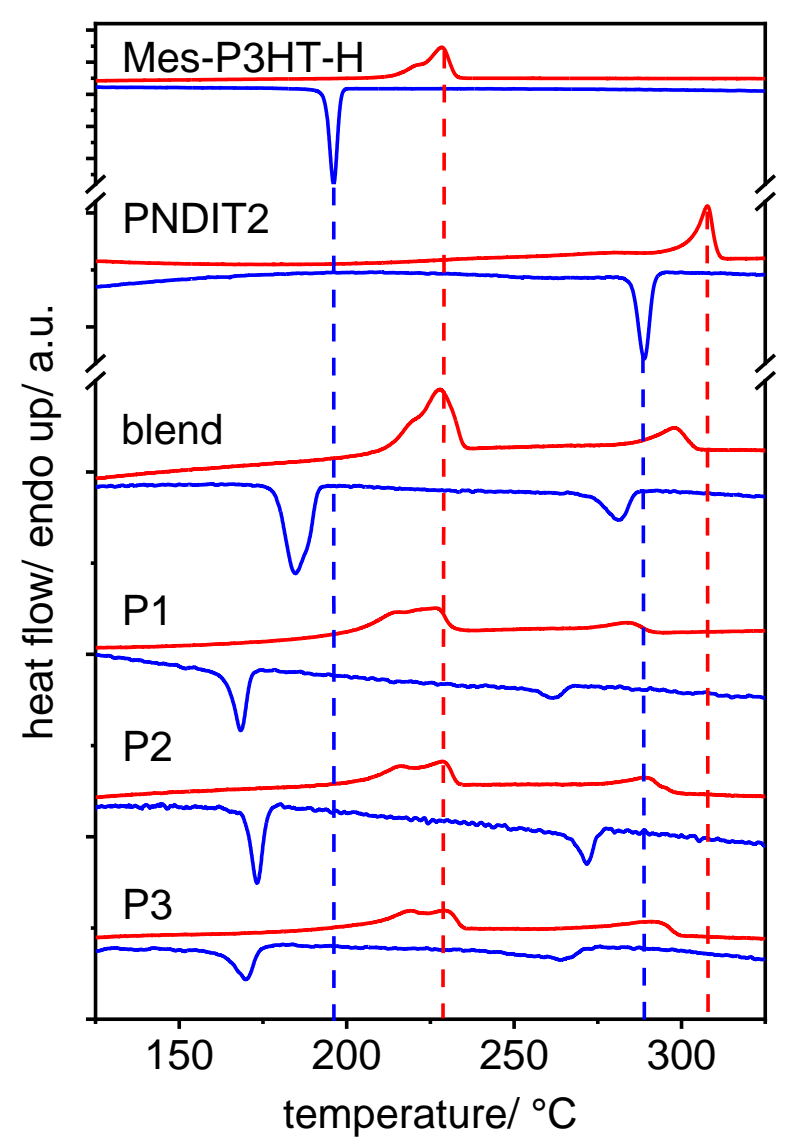

Figure 3. DSC curves of Mes-P3HT-H, PNDIT2 and the pristine blend compared to ternary samples P1, P2 and P3. In all cases, heating (red upper curve) and cooling (blue lower curve) was measured at $10 \mathrm{~K} / \mathrm{min}$. Melting (red) and crystallization (blue) peaks of the homopolymers Mes-P3HT-H and PNDIT2 are marked with dashed lines respectively.

The thermal properties are investigated by DSC (Figure 3), the estimated enthalpies and transition temperatures are summarized in Table 2. In general, the ternary samples P1, P2 and P3 show melting and crystallization features of both polymer blocks. In case of P3HT, shift in $\mathrm{T}_{\mathrm{m}}$ is weakly visible. Melting temperature $\mathrm{T}_{\mathrm{m}}$ of PNDIT2 and crystallization temperatures $T_{\mathrm{c}}$ of both polymers in the blend sample are shifted to lower temperatures compared to the pristine homopolymer. This supercooling effect is even stronger in our ternary blend systems, and can be 
explained by the covalent linkage in the $\mathrm{BCP}$ and also a lower degree of crystallinity arising from smaller crystals. The ability of both polymer blocks to crystallize is favored because of the higher degree of order and hence better charge transport within the crystals.

Table 2. Melting and crystallization enthalpies of H-P3HT-Mes, PNDIT2, blend (w:w, 1:1) of P3HT and PNDIT2 and the three samples P1, P2 and P3. Heating and cooling rates are $10 \mathrm{~K} / \mathrm{min}$ for all listed samples.

\begin{tabular}{|c|c|c|c|c|c|c|c|c|}
\hline & \multicolumn{4}{|c|}{ P3HT } & \multicolumn{4}{|c|}{ PNDIT2 } \\
\hline & $\mathrm{T}_{\mathrm{m}} /$ & $\Delta \mathrm{H}_{\mathrm{M}}{ }^{\prime}$ & $\mathrm{T}_{\mathrm{C}}{ }^{\prime}$ & $\Delta \mathrm{H}_{\mathrm{C}}{ }^{\prime}$ & $\mathrm{T}_{\mathrm{M}}{ }^{\prime}$ & $\Delta \mathrm{H}_{\mathrm{M}}{ }^{\prime}$ & $\mathrm{T}_{\mathrm{C}}{ }^{\prime}$ & $\Delta \mathrm{H}_{\mathrm{C}^{\prime}}$ \\
\hline Entry & ${ }^{\circ} \mathrm{C}$ & $\mathrm{J} / \mathrm{g}^{\mathrm{a}}$ & ${ }^{\circ} \mathrm{C}$ & $\mathrm{J} / \mathrm{g}^{\mathrm{a}}$ & ${ }^{\circ} \mathrm{C}$ & $\mathrm{J} / \mathrm{g}^{\mathrm{a}}$ & ${ }^{\circ} \mathrm{C}$ & $\mathrm{J} / \mathrm{g}^{\mathrm{a}}$ \\
\hline Mes-P3HT-H & 228 & 26.8 & 196 & 26.5 & -- & -- & -- & -- \\
\hline PNDIT2 & -- & -- & -- & -- & 308 & 8.7 & 289 & 9.3 \\
\hline blend & 228 & 24.4 & 185 & 23.0 & 298 & 7.4 & 281 & 7.8 \\
\hline P1 & 227 & 18.5 & 169 & 15.6 & 284 & 2.0 & -- & -- \\
\hline P2 & 216 & 16.5 & 173 & 8.7 & 288 & 2.5 & 272 & 5.0 \\
\hline P3 & 229 & 16.5 & 175 & 13.3 & 291 & 6.3 & 270 & 5.3 \\
\hline
\end{tabular}

${ }^{a}$ Enthalpies normalized by weight fractions.

Organic photovoltaic (OPV) devices are fabricated from as spun and thermally annealed films. $310{ }^{\circ} \mathrm{C}$ is chosen as annealing temperature based on the thermal transitions from calorimetry. In Figure 4 the $J-V$ curves and the device performance of as spun and annealed samples are compared and the photovoltaic parameters are tabulated in Table SI-1 and SI-2. The as spun samples show PCE values around $0.2 \%$, which is in agreement with reported values of 
P3HT/PNDIT2 blends systems in literature. ${ }^{30,36}$ Strikingly, melt annealing causes a drastic drop of all OPV parameters, with the ternary samples ultimately showing a weaker performance compared to the blend, indicating that a potentially beneficial influence of the block copolymer on the morphology is not the limiting factor. The trend of lower performance after melt annealing follows the pure P3HT/PNDIT2 blend as well as the BCP containing samples P1, P2 and P3.
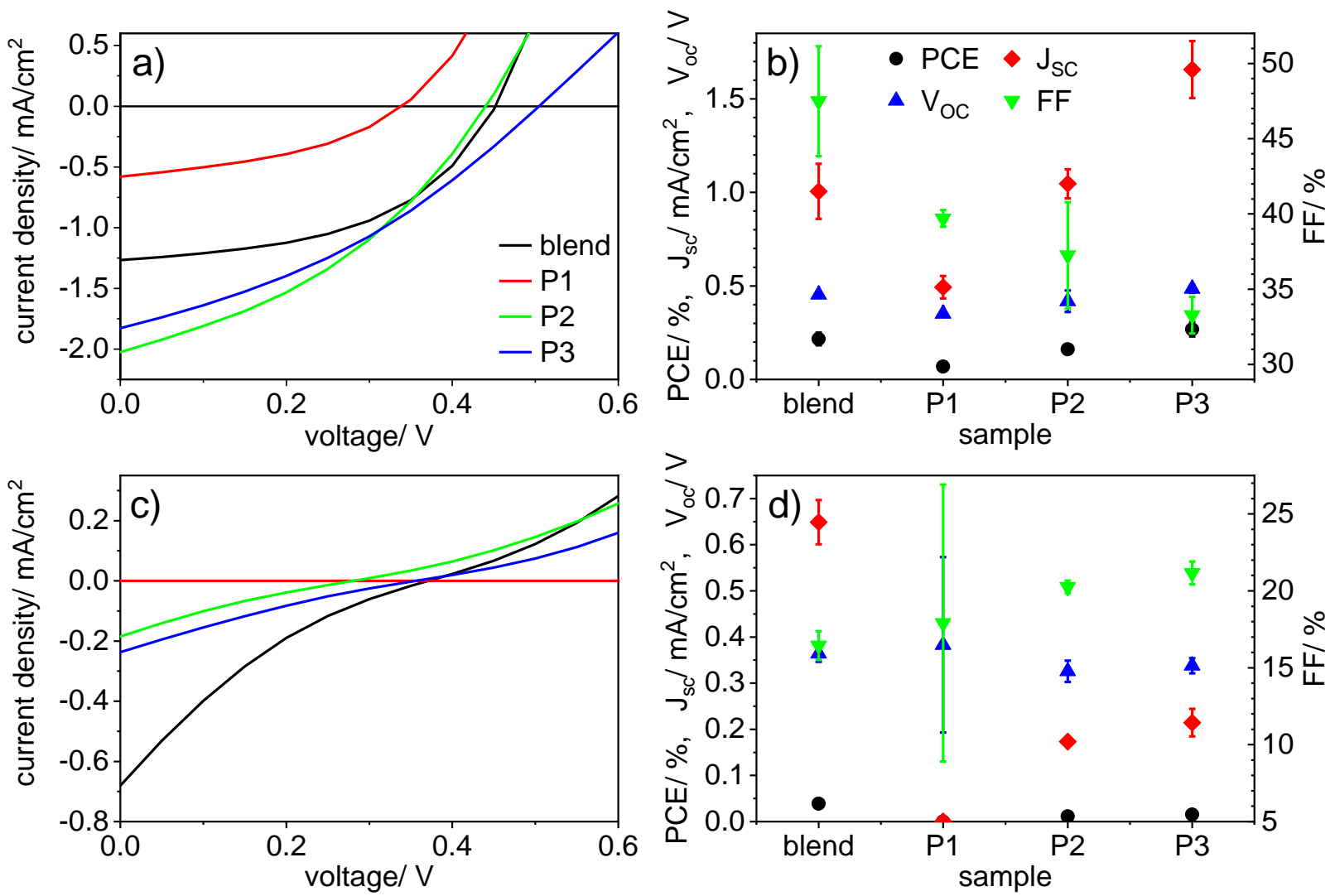

Figure 4. a) and c) J-V curves of OPV devices of P3HT/PNDIT2 blend, P1, P2 and P3 and b) and d) corresponding solar cell parameters. a) and b) Active layers as spun from chlorobenzene and c) and d) films annealed at $310{ }^{\circ} \mathrm{C}$ for 20 minutes.

To investigate the influence of the annealing temperature on the device performance, the best sample P3 is annealed at different temperatures (Figure 5, Table SI-3). Figure 5 shows two 
drastic drops in the short circuit current $J_{\mathrm{SC}}$ between $200{ }^{\circ} \mathrm{C}$ and $250{ }^{\circ} \mathrm{C}$, and between $300{ }^{\circ} \mathrm{C}$ and $310^{\circ} \mathrm{C}$. Obviously, these strong changes occur for temperature ranges in which melting the two blocks takes place. Except the fill factor, which already decreases for $\mathrm{T}<200{ }^{\circ} \mathrm{C}$, all other parameters follow the trend of the $J_{\mathrm{SC}}$.
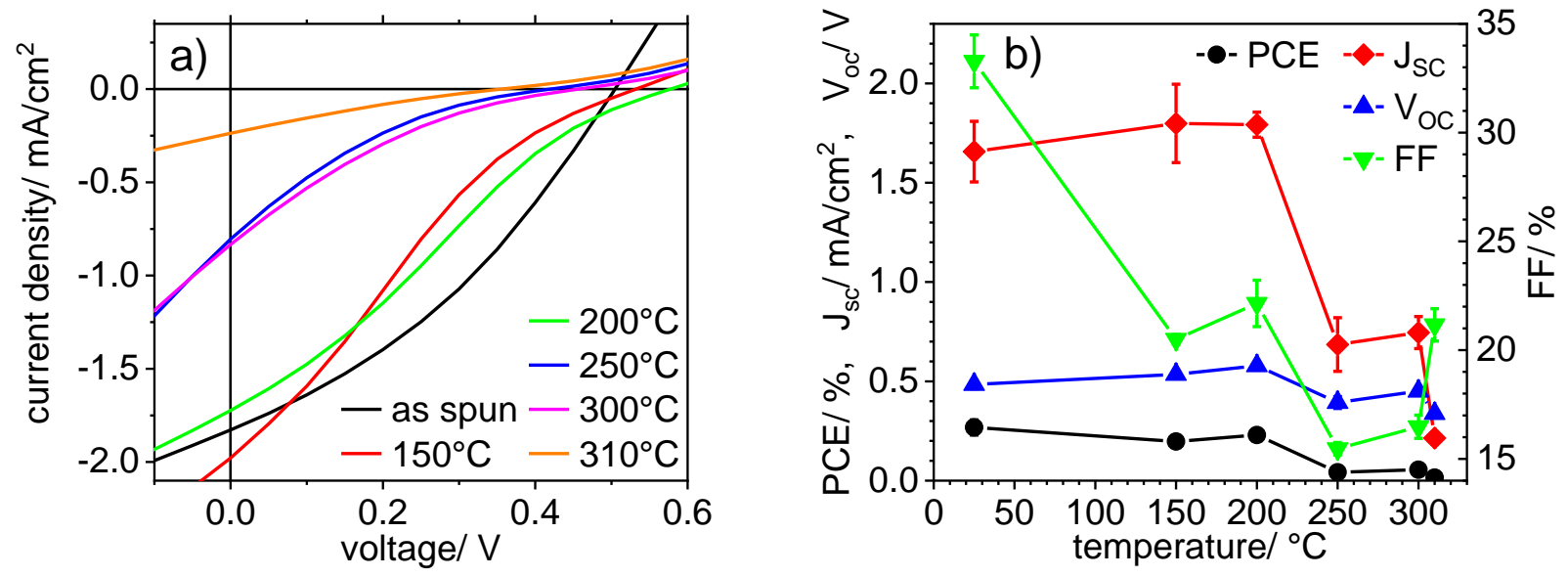

Figure 5. Influence of annealing temperature on performance of P3 with a) J-V curves of OPV devices and b) corresponding solar cell parameters.

To understand this finding, several techniques are combined to analyze the morphology. The surface morphology is imaged by atomic force microscopy (AFM). Images of all the samples as spun and annealed are inspected and additionally compared to pristine P3HT (Figure SI-2 and SI-3). Little information can be extracted from the AFM images except that the blend shows a coarser structure compared to the ternary samples. P3HT fibrils typically seen in crystalline P3HT homopolymer films are also not visible in neither the blend nor in the ternary samples.

More detailed information about structure formation within the polymer blends is accessible by grazing incidence wide- and small angle X-ray scattering (GIWAXS/GISAXS). ${ }^{59-64}$ Complete comparisons of all the samples are presented in the supporting information and only results from 
P3 are shown, since they are representative for all the BCP samples.

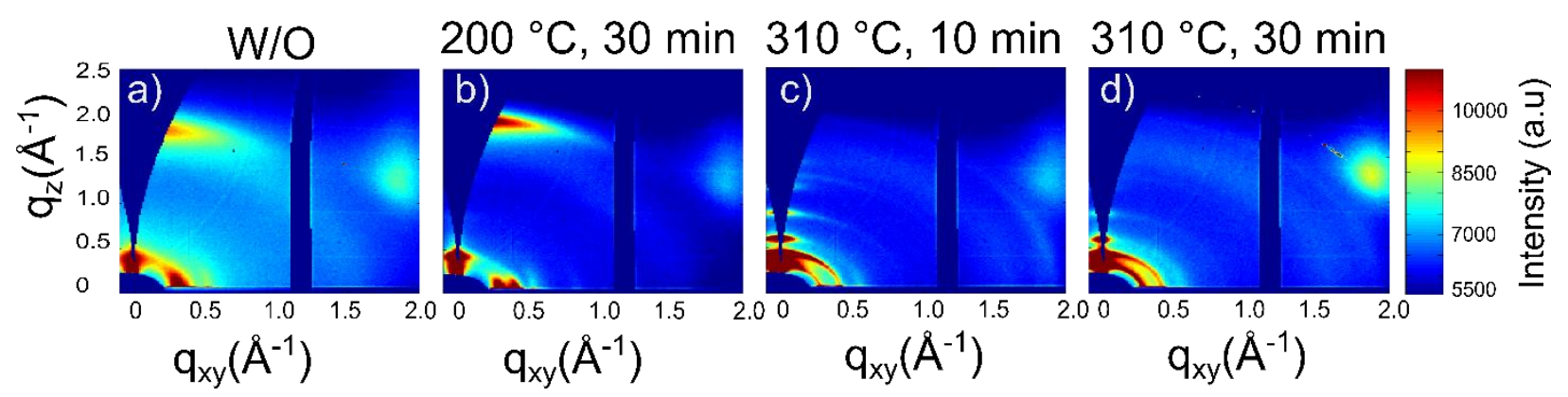

Figure 6. 2D GIWAXS data of BCP sample P3 at different annealing conditions: a) as spun, b) $200{ }^{\circ} \mathrm{C}$ for 30 minutes, c) $310{ }^{\circ} \mathrm{C}$ for 10 minutes and d) $310{ }^{\circ} \mathrm{C}$ for 30 minutes.

Selected 2D GIWAXS data in Figure 6 show a series of sample P3 treated with different annealing protocols. Signals arising along the $\mathrm{q}_{\mathrm{z}}$ axis belong to edge-on orientation and along the $\mathrm{q}_{\mathrm{xy}}$ axis to face-on orientation relative to the substrate. The Bragg reflexes intensify by rising the annealing temperature suggesting a higher degree of crystallinity due to annealing. Particularly along the $\mathrm{q}_{\mathrm{z}}$ axis the orientation becomes stronger which results in the formation of edge-on rich domains in the films. This effect appears at $310{ }^{\circ} \mathrm{C}$, which is higher than any transition temperature of both polymers. However, the influence of PNDIT2 on the polymer crystal orientation at $310{ }^{\circ} \mathrm{C}$ should be more pronounced because it favors face-on orientation already after spin coating. For further analysis, cake cuts of the 2D GIWAXS data are done along the $\mathrm{q}_{\mathrm{z}}$ and the $\mathrm{q}_{\mathrm{xy}}$ axis to obtain the vertical and horizontal information, respectively (Figure 7). While for P3 in spun cast and annealed at $200{ }^{\circ} \mathrm{C}$ most of the signals occur from face-on oriented PNDIT2, by increasing the annealing temperature to $310{ }^{\circ} \mathrm{C}$ signals along the $\mathrm{q}_{\mathrm{z}}$ axis are getting stronger and clearer while in $\mathrm{q}_{\mathrm{xy}}$ direction the degree of orientation remains constant. Edge-on oriented P3HT shows clearly visible signals along the $\mathrm{q}_{\mathrm{z}}$ direction while signals from PNDIT2 
arise by annealing at $310{ }^{\circ} \mathrm{C}$. For PNDIT2 this is attended by a reorientation from spun-cast favored face-on to melt annealed favored edge-on orientation. ${ }^{25}$ Interestingly, in the P3HT/PNDIT2 blend, the scattering signals (Figure SI-4) in as spun films and those annealed at $200{ }^{\circ} \mathrm{C}$ occur exclusively from $\mathrm{P} 3 \mathrm{HT}$ in contrast to P1-P3. This indicates that P3HT suppresses the crystallization of PNDIT2 within the blend without BCP content. Such suppression of crystallization of one component in a blend of two conjugated polymers was reported before e.g. for the system poly(3-octylthiophene-2,5-diyl) (P3OT) and poly(2,5di(hexyloxy)cyanoterephthalylidene) (CN-PPV). ${ }^{65}$
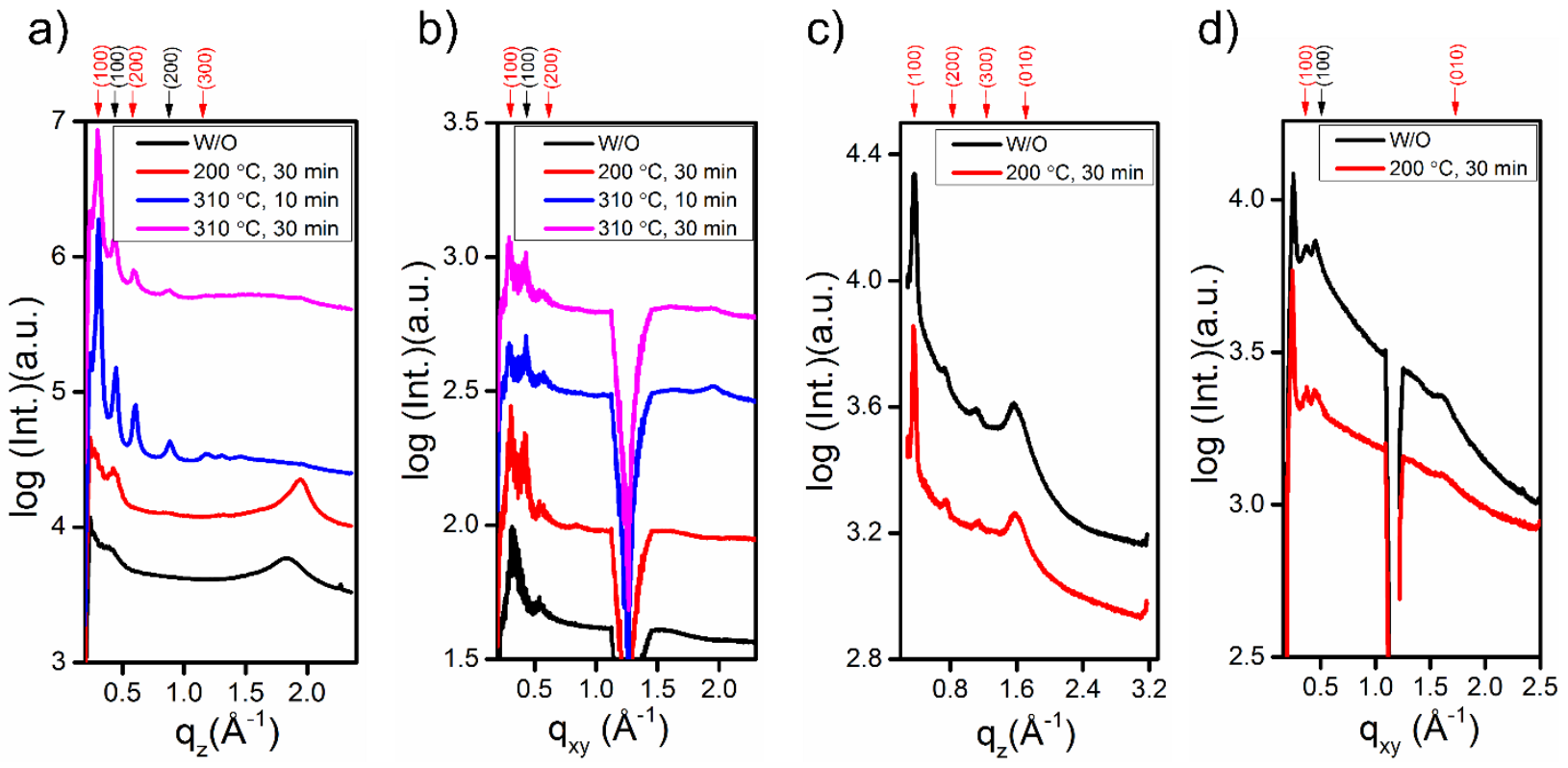

Figure 7. Vertical $(a, c)$ and horizontal cake cuts $(b, d)$ of the 2D GIWAXS data of P3 $(a, b)$ and P3HT/PNDIT2 blend $(\mathrm{c}, \mathrm{d})$. Bragg peaks related to P3HT and PNDIT2 are marked with red and black arrows and index numbers, respectively.

A detailed analysis of structures in the nanometer length scale is obtained from GISAXS measurements (Figure SI-6). Vertical line cuts of the 2D GISAXS data for P3 and blend system 
are shown in Figure 8. A broad Bragg peak arises after annealing at $310{ }^{\circ} \mathrm{C}$, indicating formation of the crystallites as seen already in the GIWAXS data. In contrast to the GIWAXS data the central part of the Bragg peak is accessible due to a significantly smaller missing wedge in reciprocal space which explains the differences in the peak shape. Thus, at $200{ }^{\circ} \mathrm{C}$ edge-on crystals are broadly distributed and weakly developed whereas at $310{ }^{\circ} \mathrm{C}$ this orientation is enhanced and well populated.

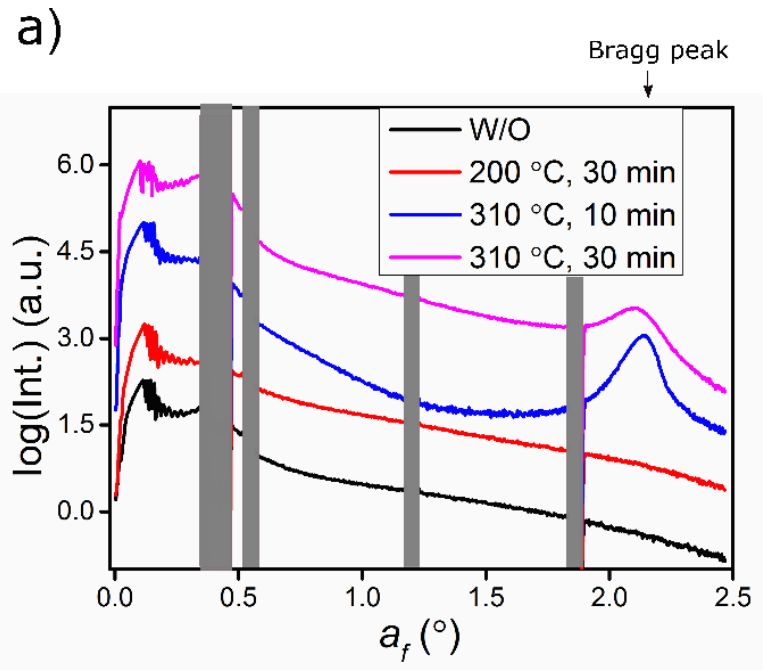

b)

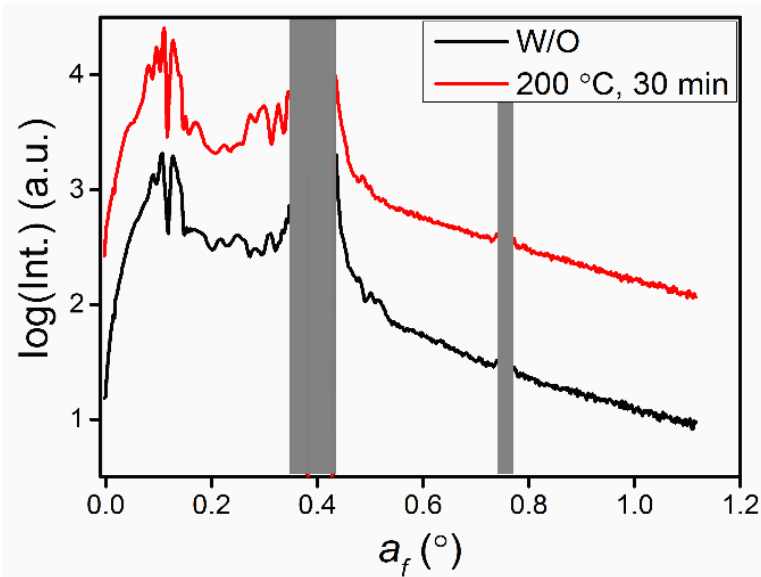

Figure 8. Vertical cuts of 2D GISAXS data of a) P3 and b) P3HT/PNDIT2 blend for different annealing conditions as indicated. The specular peak shielded with a beam stop and intermodal gaps are marked with gray areas. The Bragg peak position is indicated with an arrow.

Moreover, the Yoneda peak position can be determined from the vertical line cuts. In case of the BCP compatibilized samples it is located at $0.098^{\circ}$. From the analysis of the horizontal line cuts (Figure 9) characteristic lateral structure sizes are determined. These characteristic structures are located inside the films and describe domains. In addition, the distances between such domains are obtained from the data analysis. When modelling the GISAXS data of P3 the best agreement 
is found for a model which assumes three different object sizes and distances, meaning that the films contain three characteristic and distinct substructures. The three characteristic substructures of P3, colored as black, red and blue are in the range of 35-70 nm, 15-25 nm and lower than 10 nm, respectively. In contrast, the P3HT/PNDIT2 blend shows only two different substructures, both larger as compared to P3 which underlines a successful compatibilization effect of the BCPs in the blend.

a)
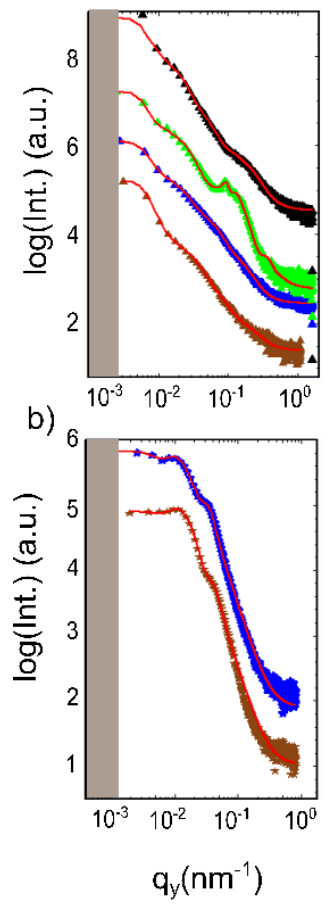

c)

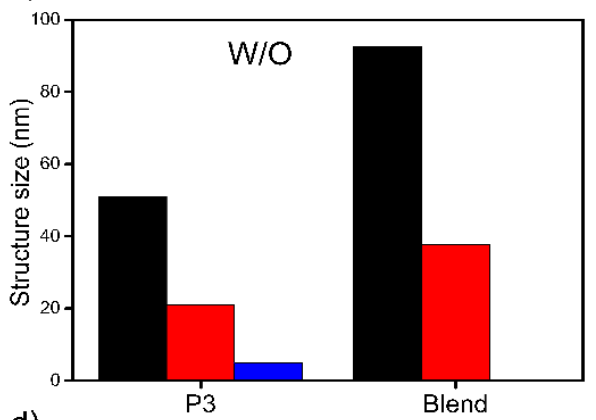

d)

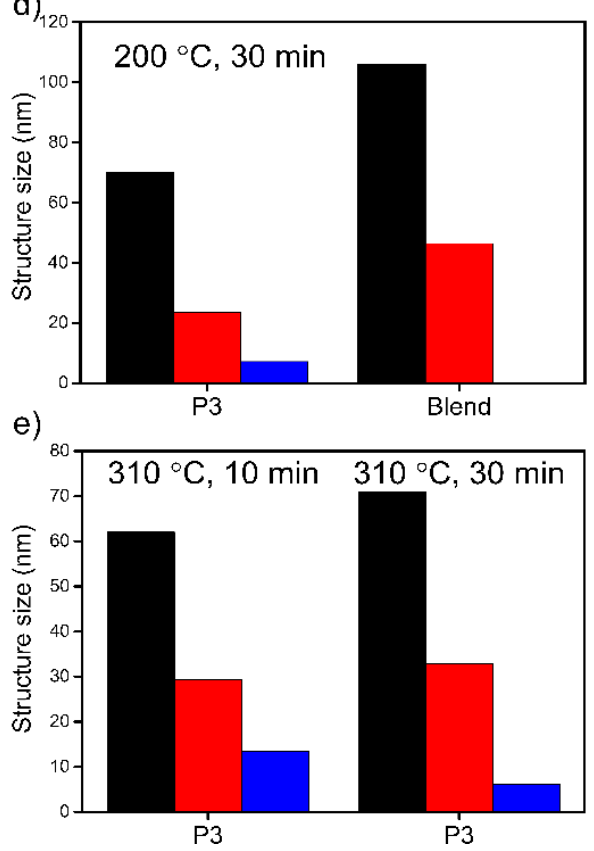

f)

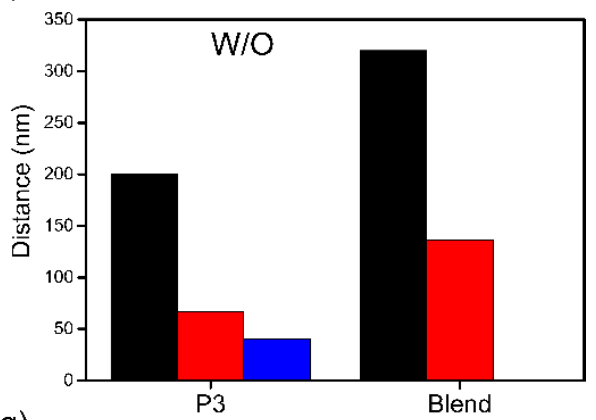

g)

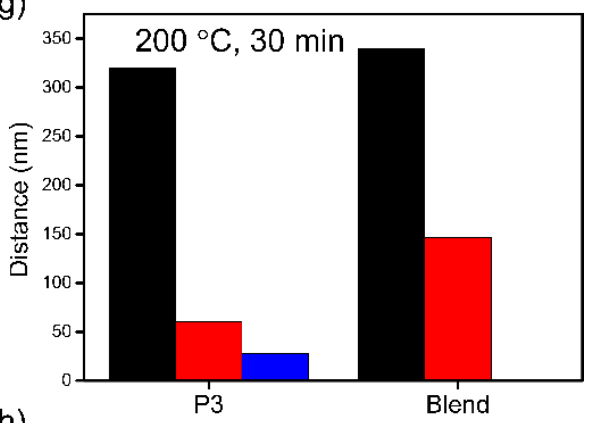

h)

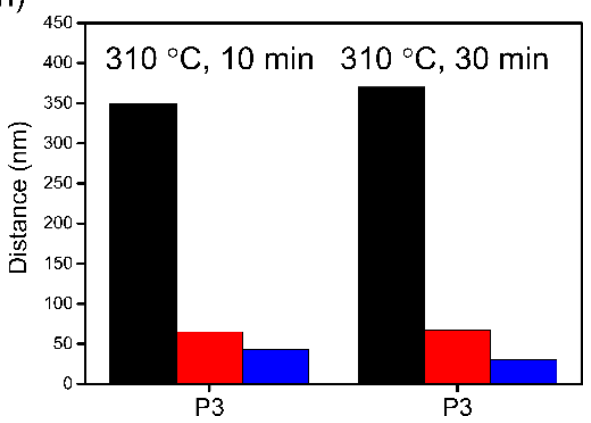

Figure 9. Horizontal line cuts 2D GISAXS data of a) P3 and b) P3HT/PNDIT2 blend system films without annealing (brown), $200{ }^{\circ} \mathrm{C}$ for 30 minutes (blue), $310{ }^{\circ} \mathrm{C}$ for 10 minutes (green) and $310{ }^{\circ} \mathrm{C}$ for 30 minutes (black) shown together with fits (red lines). (c,d,e) Structure sizes and 
$(\mathrm{f}, \mathrm{g}, \mathrm{h})$ distance as determined from modelling of the GISAXS data.

Morphology and structure of the films was further analyzed by using TEM. Samples were analyzed using both electron diffraction and low dose high resolution TEM. Figure 10 depicts the characteristic ED and HR-TEM images for the three copolymer samples. In as prepared films, HR-TEM reveals the characteristic fringed patterns that are typical of face-on oriented PNDIT2 crystals. The periodicity of the patterns is $2.25 \mathrm{~nm} \pm 0.1 \mathrm{~nm}$ for all three patterns and corresponds to the layer period between PNDIT2 backbones and layers of disordered alkyl side chains. The average in-plane dimension of the crystalline domains is rather small. It does not exceed 20-30 nm in length along both chain direction and alkyl side chains for P1. For P2 and P3, the contours of the domains are poorly defined. For P1, correlations between in-plane orientations of crystalline domains is suggested by the oriented character of the ED pattern. Indeed, using selected area electron diffraction on a few $\mu \mathrm{m}^{2}$, it is possible to observe ED patterns made of arced reflections and non-uniform Scherrer rings as expected for random inplane orientation of crystalline domains. The ED patterns of all copolymers (see Figure 10) show the typical features of crystalline PNDIT2. More specifically, the presence of the 001, 002 and 004 with a strong intensity of the 001 suggests that form I, i.e. segregated stacking of NDI and $\mathrm{T} 2$, is present in the crystalline domains of the PNDIT2 block. ${ }^{66}$ Beside the characteristic reflections of the PNDIT2 block, the ED features also a Scherrer ring at $0.38 \mathrm{~nm}$. This reflection is typical of the $\pi$-stacking in P3HT. A careful look shows that this ring is not perfectly uniform in intensity but has a slight maximum along the direction perpendicular to the chain direction of the PNDIT2 block. This observation suggests that some of the P3HT blocks are ordered such that the P3HT chains are collinear to that of PNDIT2. However, there is also a large fraction of P3HT domains with a random in-plane chain orientation that is not correlated to that of the PNDIT2 
block. Overall, from all three copolymers, P3 showed the least intense reflections in the ED patterns as compared to $\mathrm{P} 1$ and $\mathrm{P} 2$.

P1
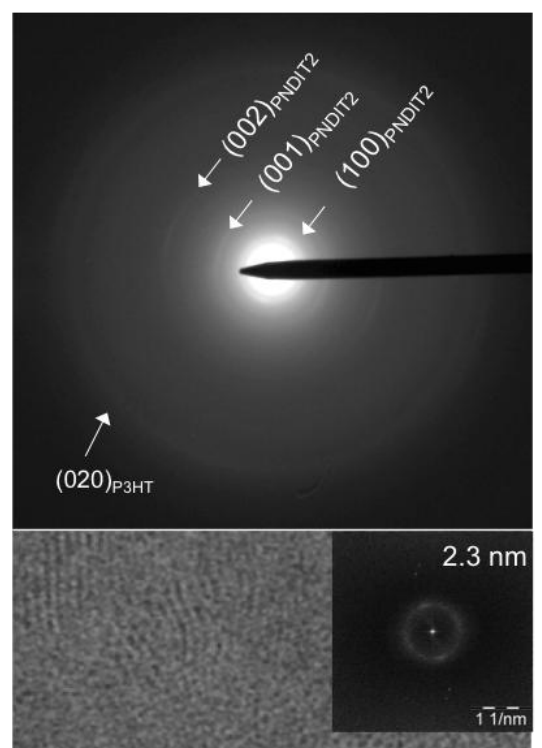

$\overline{11} / \mathrm{mm}$

$20 \mathrm{~nm}$
P2

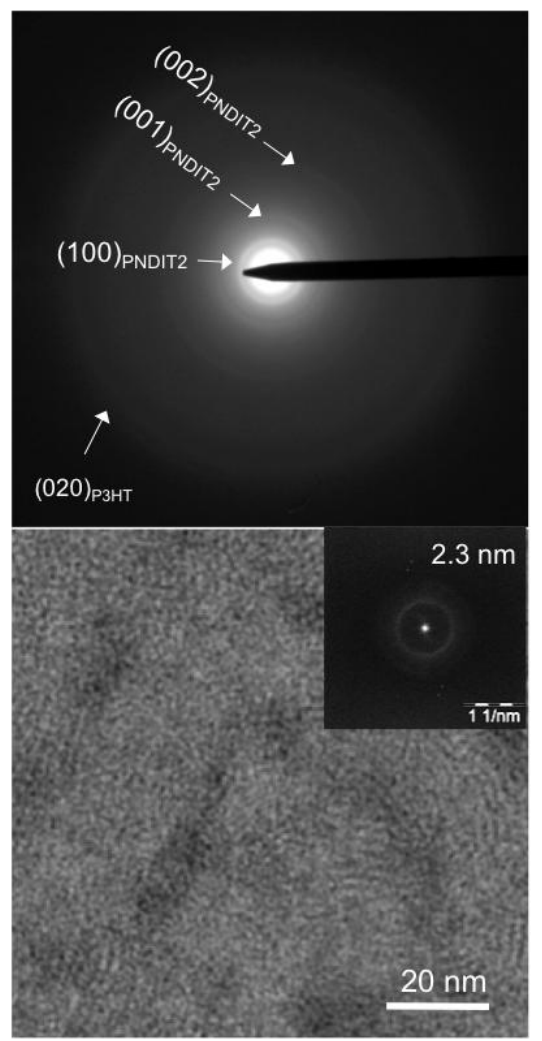

P3

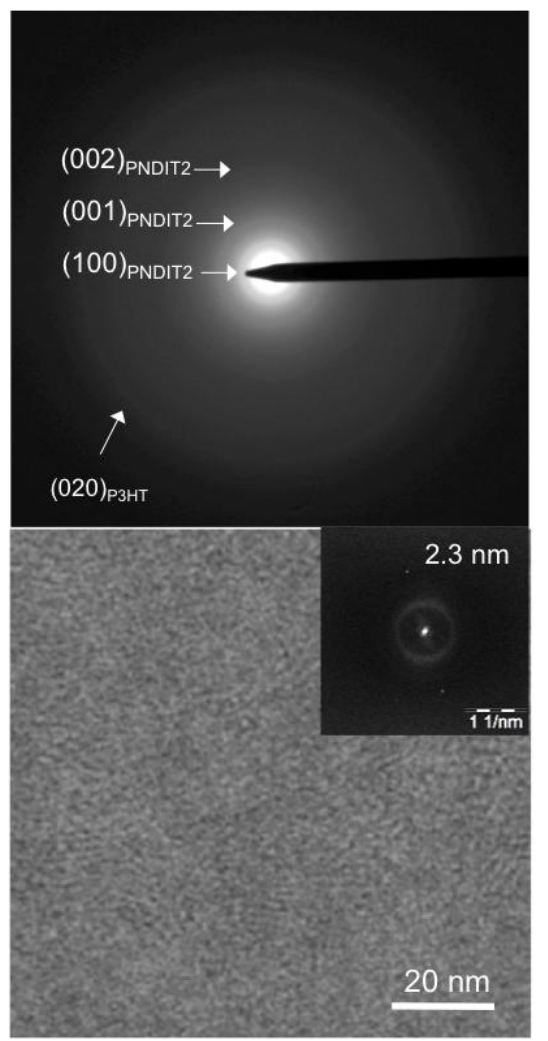

Figure 10. ED and HR-TEM images of as-cast copolymer thin films. Indexation of the most intense reflections in the ED patterns is according to the form I structure of the PNDIT2 block (see text).

TEM further helped determine the structural modifications induced by thermal annealing at $310{ }^{\circ} \mathrm{C}$. As a matter of facts, it was not possible to retrieve the annealed samples from their silicon substrates. Hence, the effect of thermal annealing at $310{ }^{\circ} \mathrm{C}$ on film morphology was observed on the TEM grids of the as-prepared samples. For all copolymer films, the ED patterns of the annealed samples were different from those of the pristine samples. The prominent $(100)_{\text {PNDIT2 }}$ reflection observed in the pristine films disappeared after annealing at $310{ }^{\circ} \mathrm{C}$, 
whereas a dominant reflection at $3.8 \AA$ appeared. In agreement with GIWAXS measurements, annealing at $310{ }^{\circ} \mathrm{C}$ induces a change in crystal orientation of the PNDIT2 blocks from flat-on to edge-on after thermal annealing. The ED pattern of P1 (see Figure 11) is characteristic of form II edge-on crystalline phase of PNDIT2, in which NDI and T2 units are stacked in a mixed mode in the PNDIT2 blocks. ${ }^{66}$ Annealed P1 samples also showed oriented ED patterns that indicated mesoscale in-plane ordering between PNDIT2 domains. Interestingly, the bright field image of this sample showed a periodic intensity modulation at a period of $\sim 29 \mathrm{~nm}$, that is tentatively attributed to phase separated domains of PNDIT2 and P3HT. In P2 and P3, this phase-separated morphology was less obvious whereas the same observations were made concerning the evolution of the ED patterns. Thus, on comparing figure 4 and 11, it is obvious that the $\sim 29 \mathrm{~nm}$ feature that developed after annealing P1 is not advantageous for device performance, which is entirely dominated by chain orientation. 
P1

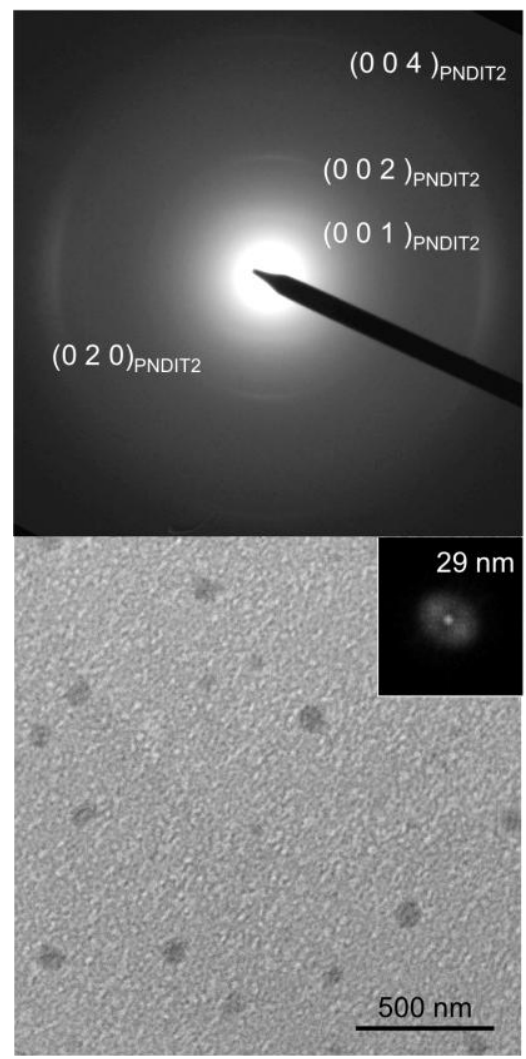

P2

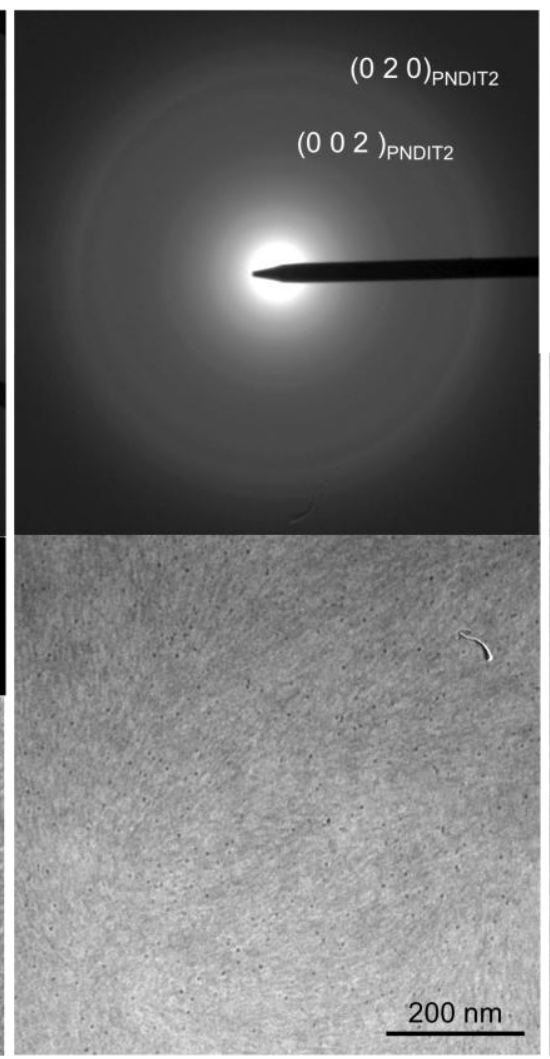

P3

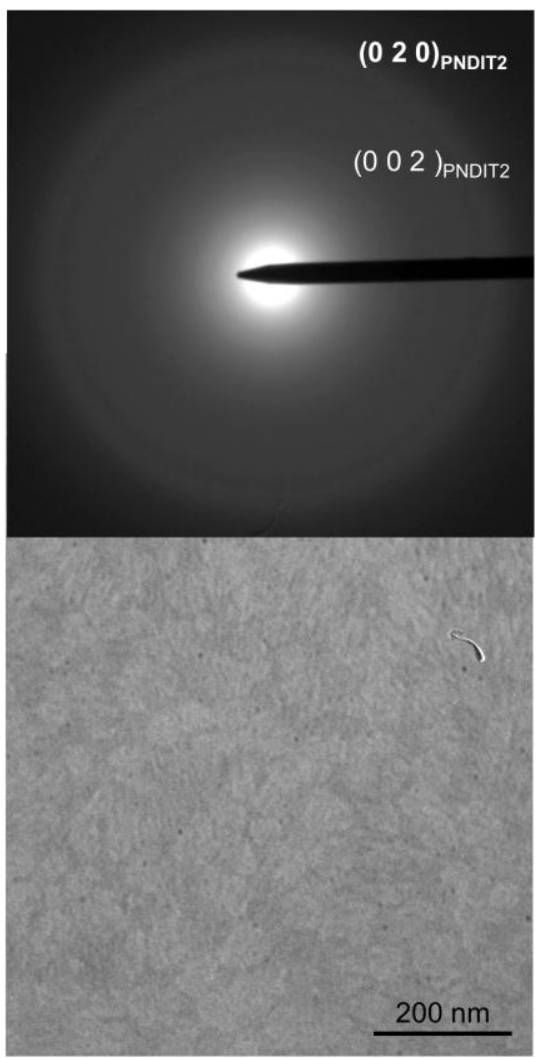

Figure 11. ED patterns and bright field images of $\mathrm{P} 1, \mathrm{P} 2$ and $\mathrm{P} 3$ copolymer thin films after annealing at $310{ }^{\circ} \mathrm{C}$. The arced reflections in the ED patterns of $\mathrm{P} 1$ features in-plane local orientation of edge-on oriented blocks of PNDIT2. The inset in the BF image of P1 corresponds to the Fast Fourier Transform. It reveals a periodic lamellar structure with a total periodicity of approx. $29 \mathrm{~nm}$.

\section{CONCLUSION}

A series of in-situ synthesized ternary block copolymer / homopolymer blends have been investigated regarding all-polymer solar cell performance. Block copolymers (BCP) can act as macromolecular surfactant at the donor-acceptor interfaces of blend systems, reduce the interfacial torsion and improve phase separation in the nm length scale. UV-vis and DSC 
investigations evidenced suitable polymer properties for OPV applications, however performance shows drastic quality fall-off due to melt-annealing of the samples. Therefore, the dependence of the annealing temperature on device performance is investigated showing two drops in performance, related to the melting temperatures of the used homo polymers. These findings guide to a further detailed morphological analysis of the samples by GIWAXS and GISAXS. GISAXS provides and understanding about the substructures inside the films and proofs that a successful compatibilization occurs by reducing the substructure sizes and distances in the samples containing $\mathrm{BCP}$, in contrast to the blend with expanded dimensions. GIWAXS shows a face-on orientation for spun cast PNDIT2 and a reorientation due to melt annealing to edge-on while P3HT consequently remains in edge-on orientation over the entire range of temperatures studied. In contrast to the BCP compatibilized blends P1-P3, with only PNDIT2 signals for as spun and samples annealed at $200{ }^{\circ} \mathrm{C}$, the P3HT/PNDIT2 blend shows only P3HT signals by treatment with these temperatures indicating suppression of the PNDIT2 crystallization by P3HT in the pristine blend. These findings are confirmed by results from HRTEM. Further, HR-TEM shows that PNDIT2 also changes the intermolecular stacking due to melt annealing from form I (segregated) to form II (mixed). ${ }^{66}$ However, combination of polymers have to be chosen carefully in matter of relative orientation and changes due to melt annealing, as can be seen in this case. In addition, the degree of compatibilization effects of $\mathrm{BCP}$ on blend systems is strongly system dependent and should be considered carefully.

\section{ASSOCIATED CONTENT}

Supporting Information. This material is available free of charge via the internet at http://pubs.acs.org. 


\section{AUTHOR INFORMATION}

Corresponding Author

*E-mail mailto:michael.sommer@chemie.tu-chemnitz.de (M.S.).

\section{ORCID}

Michael Sommer: 0000-0002-2377-5998

Author Contributions

The manuscript was written through contributions of all authors. All authors have given approval to the final version of the manuscript.

Funding Sources

The Baden-Württemberg Stiftung gGmbH (research program Clean Tech 2, project CT 2) and the Research Innovation Fund of the University of Freiburg is gratefully acknowledged for funding. P.M.-B. acknowledges funding from TUM.solar in the frame of the Bavarian Collaborative Research Project "Solar technologies go Hybrid" (SolTech) and from the International Research Training Group 2022 Alberta/Technical University of Munich International Graduate School for Environmentally Responsible Functional Hybrid Materials (ATUMS). D.Y. acknowledges the China Scholarship Council (CSC).

Notes

The authors declare no competing financial interest.

\section{ACKNOWLEDGMENT}


The authors thank M. Hagios and A. Warmbold (University of Freiburg) for SEC and DSC measurements, respectively as well as W. Ohm for help during setting up the beamline P03 at DESY.

\section{REFERENCES}

(1) Zhang, F.; Inganäs, O.; Zhou, Y.; Vandewal, K. Development of Polymer-fullerene Solar Cells. Natl. Sci. Rev. 2016, 3 (2), 222-239 DOI: 10.1093/nsr/nww020.

(2) Ryno, S. M.; Ravva, M. K.; Chen, X.; Li, H.; Brédas, J.-L. Molecular Understanding of Fullerene - Electron Donor Interactions in Organic Solar Cells. Adv. Energy Mater. 2016, 1601370 DOI: $10.1002 /$ aenm.201601370.

(3) Lu, L.; Zheng, T.; Wu, Q.; Schneider, A. M.; Zhao, D.; Yu, L. Recent Advances in Bulk Heterojunction Polymer Solar Cells. Chem. Rev. 2015, 115 (23), 12666-12731 DOI: 10.1021/acs.chemrev.5b00098.

(4) Benten, H.; Mori, D.; Ohkita, H.; Ito, S. Recent Research Progress of Polymer Donor/polymer Acceptor Blend Solar Cells. J. Mater. Chem. A 2016, 4 (15), 5340-5365 DOI: $10.1039 / \mathrm{C} 5 \mathrm{TA} 10759 \mathrm{H}$.

(5) Holliday, S.; Li, Y.; Luscombe, C. K. Recent Advances in High Performance DonorAcceptor Polymers for Organic Photovoltaics. Prog. Polym. Sci. 2017, 70, 34-51 DOI: 10.1016/j.progpolymsci.2017.03.003.

(6) Kim, T.; Kim, J.-H.; Kang, T. E.; Lee, C.; Kang, H.; Shin, M.; Wang, C.; Ma, B.; Jeong, U.; Kim, T.-S.; Kim, B. J. Flexible, Highly Efficient All-Polymer Solar Cells. Nat. Commun. 2015, 6 (May), 8547 DOI: 10.1038/ncomms9547.

(7) Li, Z.; Xu, X.; Zhang, W.; Meng, X.; Ma, W.; Yartsev, A.; Inganäs, O.; Andersson, M. R.; 
Janssen, R. A. J.; Wang, E. High Performance All-Polymer Solar Cells by Synergistic Effects of Fine-Tuned Crystallinity and Solvent Annealing. J. Am. Chem. Soc. 2016, 138 (34), 10935-10944 DOI: 10.1021/jacs.6b04822.

(8) Gao, L.; Zhang, Z.-G.; Xue, L.; Min, J.; Zhang, J.; Wei, Z.; Li, Y. All-Polymer Solar Cells Based on Absorption-Complementary Polymer Donor and Acceptor with High Power Conversion Efficiency of 8.27\%. Adv. Mater. 2016, 28 (9), 1884-1890 DOI: 10.1002/adma.201504629.

(9) Reshma, L.; Santhakumar, K. Non-Fullerene Organic Solar Cells with 7\% Efficiency and Excellent Air Stability through Morphological and Interfacial Engineering. Org. Electron. 2017, 47, 35-43 DOI: 10.1016/j.orgel.2017.05.002.

(10) Hwang, Y. J.; Courtright, B. A. E.; Ferreira, A. S.; Tolbert, S. H.; Jenekhe, S. A. 7.7\% Efficient All-Polymer Solar Cells. Adv. Mater. 2015, 27 (31), 4578-4584 DOI: 10.1002/adma.201501604.

(11) Liu, Y.; Zhao, J.; Li, Z.; Mu, C.; Ma, W.; Hu, H.; Jiang, K.; Lin, H.; Ade, H.; Yan, H. Aggregation and Morphology Control Enables Multiple Cases of High-Efficiency Polymer Solar Cells. Nat. Commun. 2014, 5 (9), 5293 DOI: 10.1038/ncomms6293.

(12) Zhao, J.; Li, Y.; Yang, G.; Jiang, K.; Lin, H.; Ade, H.; Ma, W.; Yan, H. Efficient Organic Solar Cells Processed from Hydrocarbon Solvents. Nat. Energy 2016, 1 (2), 15027 DOI: 10.1038/nenergy.2015.27.

(13) Hodgkiss, J. M.; Campbell, A. R.; Marsh, R. A.; Rao, A.; Albert-Seifried, S.; Friend, R. H. Subnanosecond Geminate Charge Recombination in Polymer-Polymer Photovoltaic Devices. Phys. Rev. Lett. 2010, 104 (17), 1-4 DOI: 10.1103/PhysRevLett.104.177701.

(14) Markov, D. E.; Amsterdam, E.; Blom, P. W. M.; Sieval, A. B.; Hummelen, J. C. Accurate 
Measurement of the Exciton Diffusion Length in a Conjugated Polymer Using a Heterostructure with a Side-Chain Cross-Linked Fullerene Layer. J. Phys. Chem. A 2005, 109 (24), 5266-5274 DOI: 10.1021/jp0509663.

(15) Dimitrov, S.; Schroeder, B.; Nielsen, C.; Bronstein, H.; Fei, Z.; McCulloch, I.; Heeney, M.;

Durrant, J. Singlet Exciton Lifetimes in Conjugated Polymer Films for Organic Solar Cells. Polymers (Basel). 2016, 8 (1), 14 DOI: 10.3390/polym8010014.

(16) Sirringhaus, H.; Brown, P. J.; Friend, R. H.; Nielsen, M. M.; Bechgaard, K.; LangeveldVoss, B. M. W.; Spiering, A. J. H.; Janssen, R. A. J.; Meijer, E. W.; Herwig, P.; de Leeuw, D. M. Two-Dimensional Charge Transport in Self-Organized, High-Mobility Conjugated Polymers. Nature 1999, 401 (6754), 685-688 DOI: 10.1038/44359.

(17) Tremel, K.; Fischer, F. S. U.; Kayunkid, N.; Pietro, R. Di; Tkachov, R.; Kiriy, A.; Neher, D.; Ludwigs, S.; Brinkmann, M. Charge Transport Anisotropy in Highly Oriented Thin Films of the Acceptor Polymer P(NDI2OD-T2). Adv. Energy Mater. 2014, 4 (10), 1301659 DOI: 10.1002/aenm.201301659.

(18) Matsidik, R.; Luzio, A.; Askin, Ö.; Fazzi, D.; Sepe, A.; Steiner, U.; Komber, H.; Caironi, M.; Sommer, M. Highly Planarized Naphthalene Diimide-Bifuran Copolymers with Unexpected Charge Transport Performance. Chem. Mater. 2017, 29 (13), 5473-5483 DOI: 10.1021/acs.chemmater.6b05313.

(19) Fabiano, S.; Yoshida, H.; Chen, Z.; Facchetti, A.; Loi, M. A. Orientation-Dependent Electronic Structures and Charge Transport Mechanisms in Ultrathin Polymeric NChannel Field-Effect Transistors. ACS Appl. Mater. Interfaces 2013, 5 (10), 4417-4422 DOI: $10.1021 / \mathrm{am} 400786 \mathrm{c}$.

(20) Kang, H.; Kim, K.-H.; Choi, J.; Lee, C.; Kim, B. J. High-Performance All-Polymer Solar 
Cells Based on Face-On Stacked Polymer Blends with Low Interfacial Tension. ACS Macro Lett. 2014, 3 (10), 1009-1014 DOI: 10.1021/mz500415a.

(21) Schuettfort, T.; Huettner, S.; Lilliu, S.; Macdonald, J. E.; Thomsen, L.; McNeill, C. R. Surface and Bulk Structural Characterization of a High-Mobility Electron-Transporting Polymer. Macromolecules 2011, 44 (6), 1530-1539 DOI: 10.1021/ma102451b.

(22) Jung, J.; Lee, W.; Lee, C.; Ahn, H.; Kim, B. J. Controlling Molecular Orientation of Naphthalenediimide-Based Polymer Acceptors for High Performance All-Polymer Solar Cells. Adv. Energy Mater. 2016, 6 (15), 1600504 DOI: 10.1002/aenm.201600504.

(23) Rivnay, J.; Toney, M. F.; Zheng, Y.; Kauvar, I. V.; Chen, Z.; Wagner, V.; Facchetti, A.; Salleo, A. Unconventional Face-On Texture and Exceptional In-Plane Order of a High Mobility N-Type Polymer. Adv. Mater. 2010, 22 (39), 4359-4363 DOI: 10.1002/adma.201001202.

(24) Anton, A. M.; Steyrleuthner, R.; Kossack, W.; Neher, D.; Kremer, F. Spatial Orientation and Order of Structure-Defining Subunits in Thin Films of a High Mobility N-Type Copolymer. $\quad$ Macromolecules 2016, $49 \quad$ (5), $\quad$ 1798-1806 DOI: 10.1021/acs.macromol.5b02420.

(25) Rivnay, J.; Steyrleuthner, R.; Jimison, L. H.; Casadei, A.; Chen, Z.; Toney, M. F.; Facchetti, A.; Neher, D.; Salleo, A. Drastic Control of Texture in a High Performance N-Type Polymeric Semiconductor and Implications for Charge Transport. Macromolecules 2011, 44 (13), 5246-5255 DOI: 10.1021/ma200864s.

(26) Zerson, M.; Neumann, M.; Steyrleuthner, R.; Neher, D.; Magerle, R. Surface Structure of Semicrystalline Naphthalene Diimide-Bithiophene Copolymer Films Studied with Atomic Force Microscopy. Macromolecules 2016, 49 (17), $6549-6557$ DOI: 
10.1021/acs.macromol.6b00988.

(27) Balko, J.; Portale, G.; Lohwasser, R. H.; Thelakkat, M.; Thurn-Albrecht, T. Surface Induced Orientation and Vertically Layered Morphology in Thin Films of poly(3Hexylthiophene) Crystallized from the Melt. J. Mater. Res. 2017, 32 (10), 1957-1968 DOI: 10.1557/jmr.2017.107.

(28) Sepe, A.; Rong, Z.; Sommer, M.; Vaynzof, Y.; Sheng, X.; Müller-Buschbaum, P.; Smilgies, D.-M.; Tan, Z.-K.; Yang, L.; Friend, R. H.; Steiner, U.; Hüttner, S. Structure Formation in P3HT/F8TBT Blends. Energy Environ. Sci. 2014, 7 (5), 1725 DOI: 10.1039/c3ee44125c.

(29) Schubert, M.; Collins, B. A.; Mangold, H.; Howard, I. A.; Schindler, W.; Vandewal, K.; Roland, S.; Behrends, J.; Kraffert, F.; Steyrleuthner, R.; Chen, Z.; Fostiropoulos, K.; Bittl, R.; Salleo, A.; Facchetti, A.; Laquai, F.; Ade, H. W.; Neher, D. Correlated Donor/Acceptor Crystal Orientation Controls Photocurrent Generation in All-Polymer Solar Cells. Adv. Funct. Mater. 2014, 24 (26), 4068-4081 DOI: 10.1002/adfm.201304216.

(30) Moore, J. R.; Albert-Seifried, S.; Rao, A.; Massip, S.; Watts, B.; Morgan, D. J.; Friend, R. H.; McNeill, C. R.; Sirringhaus, H. Polymer Blend Solar Cells Based on a High-Mobility Naphthalenediimide-Based Polymer Acceptor: Device Physics, Photophysics and Morphology. Adv. Energy Mater. 2011, 1 (2), 230-240 DOI: 10.1002/aenm.201000035.

(31) Mori, D.; Benten, H.; Kosaka, J.; Ohkita, H.; Ito, S.; Miyake, K. Polymer/Polymer Blend Solar Cells with 2.0\% Efficiency Developed by Thermal Purification of Nanoscale-PhaseSeparated Morphology. ACS Appl. Mater. Interfaces 2011, 3 (8), 2924-2927 DOI: $10.1021 / \mathrm{am} 200624 \mathrm{~s}$.

(32) Fabiano, S.; Himmelberger, S.; Drees, M.; Chen, Z.; Altamimi, R. M.; Salleo, A.; Loi, M. A.; Facchetti, A. Charge Transport Orthogonality in All-Polymer Blend Transistors, 
Diodes, and Solar Cells. Adv. Energy Mater. 2014, 4 (6), 1301409 DOI: 10.1002/aenm.201301409.

(33) Ruderer, M. A.; Wang, C.; Schaible, E.; Hexemer, A.; Xu, T.; Müller-Buschbaum, P. Morphology and Optical Properties of P3HT:MEH-CN-PPV Blend Films. Macromolecules 2013, 46 (11), 4491-4501 DOI: 10.1021/ma4006999.

(34) Mueller, C. J.; Gann, E.; Singh, C. R.; Thelakkat, M.; McNeill, C. R. Control of Molecular Orientation in Polydiketopyrrolopyrrole Copolymers via Diffusive Noncovalent Interactions. Chem. Mater. 2016, $28 \quad$ (19), 7088-7097 DOI: 10.1021/acs.chemmater.6b03245.

(35) Lombeck, F.; Sepe, A.; Thomann, R.; Friend, R. H.; Sommer, M. Compatibilization of AllConjugated Polymer Blends for Organic Photovoltaics. ACS Nano 2016, 10 (8), 80878096 DOI: 10.1021/acsnano.6b04244.

(36) Fabiano, S.; Chen, Z.; Vahedi, S.; Facchetti, A.; Pignataro, B.; Loi, M. a. Role of Photoactive Layer Morphology in High Fill Factor All-Polymer Bulk Heterojunction Solar Cells. J. Mater. Chem. 2011, 21 (16), 5891 DOI: 10.1039/c0jm03405c.

(37) Zhou, N.; Lin, H.; Lou, S. J.; Yu, X.; Guo, P.; Manley, E. F.; Loser, S.; Hartnett, P.; Huang, H.; Wasielewski, M. R.; Chen, L. X.; Chang, R. P. H.; Facchetti, A.; Marks, T. J. Morphology-Performance Relationships in High-Efficiency All-Polymer Solar Cells. Adv. Energy Mater. 2014, 4 (3), 1300785 DOI: 10.1002/aenm.201300785.

(38) Lee, C.; Li, Y.; Lee, W.; Lee, Y.; Choi, J.; Kim, T.; Wang, C.; Gomez, E. D.; Woo, H. Y.; Kim, B. J. Correlation between Phase-Separated Domain Sizes of Active Layer and Photovoltaic Performances in All-Polymer Solar Cells. Macromolecules 2016, 49 (14), 5051-5058 DOI: 10.1021/acs.macromol.6b01069. 
(39) McNeill, C. R. Morphology of All-Polymer Solar Cells. Energy Environ. Sci. 2012, 5 (2), 5653 DOI: 10.1039/c2ee03071c.

(40) Veenstra, S. C.; Loos, J.; Kroon, J. M. Nanoscale Structure of Solar Cells Based on Pure Conjugated Polymer Blends. Prog. Photovoltaics Res. Appl. 2007, 15 (8), 727-740 DOI: 10.1002/pip.796.

(41) Bates, F. S.; Fredrickson, G. H. Block Copolymers-Designer Soft Materials. Phys. Today 1999, 52 (2), 32-38 DOI: 10.1063/1.882522.

(42) Lohwasser, R. H.; Gupta, G.; Kohn, P.; Sommer, M.; Lang, A. S.; Thurn-Albrecht, T.; Thelakkat, M. Phase Separation in the Melt and Confined Crystallization as the Key to Well-Ordered Microphase Separated Donor-Acceptor Block Copolymers. Macromolecules 2013, 46 (11), 4403-4410 DOI: 10.1021/ma3021147.

(43) Lombeck, F.; Komber, H.; Sepe, A.; Friend, R. H.; Sommer, M. Enhancing Phase Separation and Photovoltaic Performance of All-Conjugated Donor-Acceptor Block Copolymers with Semifluorinated Alkyl Side Chains. Macromolecules 2015, 48 (21), 7851-7860 DOI: 10.1021/acs.macromol.5b01845.

(44) Segalman, R. A.; McCulloch, B.; Kirmayer, S.; Urban, J. J. Block Copolymers for Organic Optoelectronics. Macromolecules 2009, 42 (23), 9205-9216 DOI: 10.1021/ma901350w.

(45) Scherf, U.; Gutacker, A.; Koenen, N. All-Conjugated Block Copolymers. Acc. Chem. Res. 2008, 41 (9), 1086-1097 DOI: 10.1021/ar7002539.

(46) Sommer, M.; Huettner, S.; Thelakkat, M. Donor-acceptor Block Copolymers for Photovoltaic Applications. J. Mater. Chem. 2010, 20 (48), 10788 DOI: 10.1039/c0jm00665c.

(47) Lee, Y.; Gomez, E. D. Challenges and Opportunities in the Development of Conjugated 
Block Copolymers for Photovoltaics. Macromolecules 2015, 48 (20), 7385-7395 DOI: 10.1021/acs.macromol.5b00112.

(48) Utracki, L. a. Compatibilization of Polymer Blends. Can. J. Chem. Eng. 2002, 80 (6), 1008-1016 DOI: 10.1002/cjce.5450800601.

(49) Ryan, A. J. Polymer Science: Designer Polymer Blends. Nat. Mater. 2002, 1 (1), 8-10 DOI: $10.1038 /$ nmat720.

(50) Ruzette, A.-V.; Leibler, L. Block Copolymers in Tomorrow's Plastics. Nat. Mater. 2005, 4 (1), 19-31 DOI: 10.1038/nmat1295.

(51) Schubert, M.; Dolfen, D.; Frisch, J.; Roland, S.; Steyrleuthner, R.; Stiller, B.; Chen, Z.; Scherf, U.; Koch, N.; Facchetti, A.; Neher, D. Influence of Aggregation on the Performance of All-Polymer Solar Cells Containing Low-Bandgap Naphthalenediimide Copolymers. Adv. Energy Mater. 2012, 2 (3), 369-380 DOI: 10.1002/aenm.201100601.

(52) Holcombe, T. W.; Norton, J. E.; Rivnay, J.; Woo, C. H.; Goris, L.; Piliego, C.; Griffini, G.; Sellinger, A.; Brédas, J. L.; Salleo, A.; Fréchet, J. M. J. Steric Control of the Donor/acceptor Interface: Implications in Organic Photovoltaic Charge Generation. J. Am. Chem. Soc. 2011, 133 (31), 12106-12114 DOI: 10.1021/ja203235z.

(53) Roland, S.; Schubert, M.; Collins, B. A.; Kurpiers, J.; Chen, Z.; Facchetti, A.; Ade, H.; Neher, D. Fullerene-Free Polymer Solar Cells with Highly Reduced Bimolecular Recombination and Field-Independent Charge Carrier Generation. J. Phys. Chem. Lett. 2014, 5 (16), 2815-2822 DOI: 10.1021/jz501506z.

(54) Nübling, F.; Komber, H.; Sommer, M. All-Conjugated, All-Crystalline Donor-Acceptor Block Copolymers P3HT- B -PNDIT2 via Direct Arylation Polycondensation. Macromolecules 2017, 50 (5), 1909-1918 DOI: 10.1021/acs.macromol.7b00251. 
(55) Matsidik, R.; Komber, H.; Luzio, A.; Caironi, M.; Sommer, M. Defect-Free Naphthalene Diimide Bithiophene Copolymers with Controlled Molar Mass and High Performance via Direct Arylation Polycondensation. J. Am. Chem. Soc. 2015, 137 (20), 6705-6711 DOI: 10.1021/jacs.5b03355.

(56) Lohwasser, R. H.; Thelakkat, M. Toward Perfect Control of End Groups and Polydispersity in Poly(3-Hexylthiophene) via Catalyst Transfer Polymerization. Macromolecules 2011, 44 (9), 3388-3397 DOI: 10.1021/ma200119s.

Buffet, A.; Rothkirch, A.; Döhrmann, R.; Körstgens, V.; Abul Kashem, M. M.; Perlich, J.; Herzog, G.; Schwartzkopf, M.; Gehrke, R.; Müller-Buschbaum, P.; Roth, S. V. P03, the Microfocus and Nanofocus X-Ray Scattering (MiNaXS) Beamline of the PETRA III Storage Ring: The Microfocus Endstation. J. Synchrotron Radiat. 2012, 19 (4), 647-653 DOI: $10.1107 /$ S0909049512016895.

(58) Brinkmann, M.; Rannou, P. Molecular Weight Dependence of Chain Packing and Semicrystalline Structure in Oriented Films of Regioregular Poly(3-Hexylthiophene) Revealed by High-Resolution Transmission Electron Microscopy. Macromolecules 2009, 42 (4), 1125-1130 DOI: 10.1021/ma8023415.

(59) Müller-Buschbaum, P. GISAXS and GISANS as Metrology Technique for Understanding the 3D Morphology of Block Copolymer Thin Films. Eur. Polym. J. 2016, 81, 470-493 DOI: 10.1016/j.eurpolymj.2016.04.007.

(60) Renaud, G.; Lazzari, R.; Leroy, F. Probing Surface and Interface Morphology with Grazing Incidence Small Angle X-Ray Scattering. Surf. Sci. Rep. 2009, 64 (8), 255-380 DOI: $10.1016 /$ j.surfrep.2009.07.002.

(61) Jiang, Z.; Lee, D. R.; Narayanan, S.; Wang, J.; Sinha, S. K. Waveguide-Enhanced 
Grazing-Incidence Small-Angle X-Ray Scattering of Buried Nanostructures in Thin Films. Phys. Rev. B 2011, 84 (7), 75440 DOI: 10.1103/PhysRevB.84.075440.

(62) Ruderer, M. a.; Müller-Buschbaum, P. Morphology of Polymer-Based Bulk Heterojunction Films for Organic Photovoltaics. Soft Matter 2011, 7 (12), 5482 DOI: $10.1039 / \mathrm{c} 0 \mathrm{sm} 01502 \mathrm{~d}$.

(63) Müller-Buschbaum, P. The Active Layer Morphology of Organic Solar Cells Probed with Grazing Incidence Scattering Techniques. Adv. Mater. 2014, 26 (46), 7692-7709 DOI: 10.1002/adma.201304187.

(64) Yamamoto, K. Grazing-Incidence Small Angle X-Ray Scattering in Polymer Thin Films Utilizing Low-Energy X-Rays. In X-ray Scattering; InTech, 2017; pp 61-88.

(65) Ruderer, M. A.; Prams, S. M.; Rawolle, M.; Zhong, Q.; Perlich, J.; Roth, S. V.; MüllerBuschbaum, P. Influence of Annealing and Blending of Photoactive Polymers on Their Crystalline Structure. J. Phys. Chem. B 2010, 114 (47), 15451-15458 DOI: 10.1021/jp106972s.

(66) Brinkmann, M.; Gonthier, E.; Bogen, S.; Tremel, K.; Ludwigs, S.; Hufnagel, M.; Sommer, M. Segregated versus Mixed Interchain Stacking in Highly Oriented Films of Naphthalene Diimide Bithiophene Copolymers. ACS Nano 2012, 6 (11), 10319-10326 DOI: $10.1021 / \mathrm{nn} 304213 \mathrm{~h}$. 
TOC:

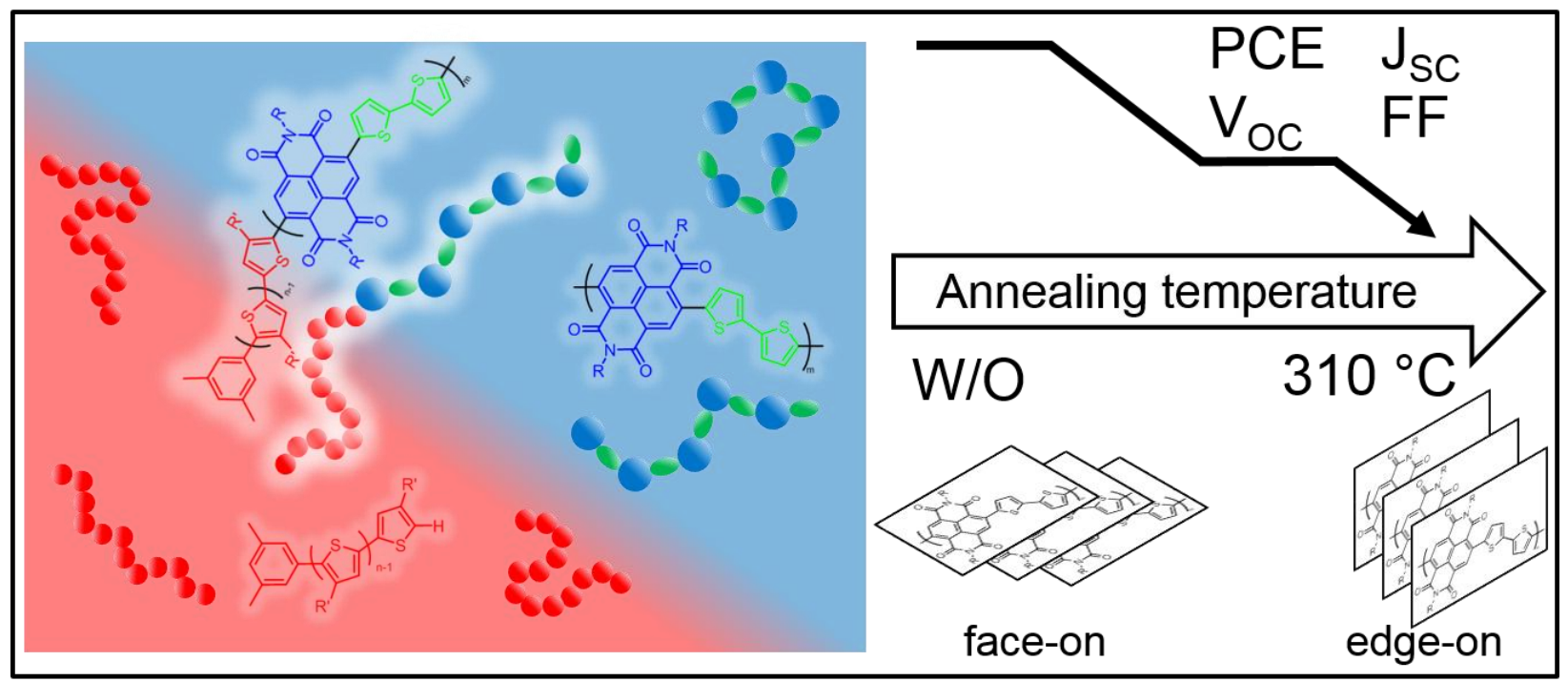

